Article

\title{
Determination of Deflection of the Vertical Components: Im- plications on Terrestrial Geodetic Measurement
}

\author{
Daniel D. Basil, Lawrence Hart*, Kurotamuno P. Jackson, Tamunobelema Oba \\ Department of Surveying and Geomatics, Faculty of Environmental Sciences, Rivers State University, Port \\ Harcourt, Nigeria \\ *Correspondence: Lawrence.hart@rsu.edu.ng
}

How to cite this paper: Basil, D. D., Hart, L., P. Jackson, K., \& Oba, T. (2021). Determination of Deflection of the Vertical Components: Im-plications on Terrestrial Geodetic

Measurement. World Journal of Geomatics and Geosciences, 1(1), 36-49. Retrieved from https://www.scipublications.com/journal/index.php/wjgg/article/view/104
Received: August 2, 2021

Accepted: November 15, 2021

Published: November 16, 2021

Copyright: (C) 2021 by the authors. Submitted for possible open access publication under the terms and conditions of the Creative Commons Attribution (CC BY) license (http://creativecommons.org/licenses /by/4.0/).

\begin{abstract}
The deflection of the vertical is an important parameter that combines both physical (astronomic) and geometric (geodetic) quantities. It is critical in such areas as datum transformation, reduction of astronomic observation to the geodetic reference surface, geoid modelling and geophysical prospecting. Although the deflection of the vertical is a physical property of the gravitational field of the earth; which almost all terrestrial survey measurements, with the exception of spatial distances, made on the earth surface are with respect to the Earth's gravity vector, because a spirit bubble is usually used to align survey instruments. It has been ignored in most geodetic computation and adjustment. This research work is therefore aimed at computing the component of the deflection of the vertical component for part of Rivers State using a geometric method. This method involves the integration of Global Positioning System (GPS) to obtain the geodetic coordinate of points, precisely levelling to obtain the orthometric height of this point located within the study area. By least square using MATLAB program, the estimated deflections of vertical component parameters for the test station SVG/GPS-002 were; -0.0473" and 0.0393" arc seconds for the north-south and east-west components respectively. The associated standard errors of the North-south and Eastwest components were $\pm 0.0093^{\prime \prime}$ and $\pm 0.0060^{\prime \prime}$ arc seconds, respectively. The deflection of the vertical was also computed independently from gravimetric models of the earth as: $\xi=0.0204^{\prime \prime} \pm 0.0008814^{\prime \prime}$, $\eta=-0.0345^{\prime \prime} \pm 0.0014^{\prime \prime} ; \xi=0.0157^{\prime \prime} \pm 0.000755^{\prime \prime}, \eta=-0.0246^{\prime \prime} \pm 0.0012^{\prime \prime} ; \xi=-0.0546 \pm 0.0006014, \eta=-$ $0.0208 \pm 0.0006014$ for EGM 2008, EGM 1996 and EGM 1984 respectively. The two-tailed hypothesis test reveals that the estimated deflection component is statistically correct at $95 \%$ confidence interval. It was observed that the effect of the deflection of the vertical is directly proportional to the distance of the geodetic baseline. Therefore, including the derived component of deflection of the vertical to the ellipsoidal model will yield high observational accuracy since an ellipsoidal model is not tenable due to its far observational error in the determination of high-quality job. It is important to include the determined deflection of the vertical component for Rivers State, Nigeria.
\end{abstract}

Keywords: Geometric, Deflection of the Vertical, Least Squares Adjustment, GPS, Coordinate

\section{Introduction}

One of the several problems in the Nigerian Geodetic Datum (Minna Datum) System and most topocentric datum is the complete ignorance and false assumption that the deflection of the vertical in defining their origin as is inconsequential [1]. This has led to difficulties in determining uniquely sets of transformational parameters; which is critical to transform the coordinates of point and spatial object from our local datum (Minna Datum) which most of our geodetic infrastructure is hinged upon to the current World Geodetic Datum (WGS) 1984; upon which the Global Positioning System (GPS) most widely used by surveyors and Geodesist is based on [2]. The component of the deflection of the vertical is very critical in the orientation of the axis of the local topocentric system with respect to the geoid and also in datum transformation, astrogeodetic geoid modelling and 
geophysical prospecting. The deflection of the vertical which represent the angular separation between the geodetic normal and the vertical to the geoid, an also be represented as the slope of the geoid with respect to the ellipsoid [3,4]. It is a physical property of the earth of gravity field that has been ignored in most geodetic computation and adjustment [5]. Various method has been developed for the determination of the component of the deflection of the vertical. The foremost being the astronomic method [6]. It can also be determined purely from gravity measurement through the use of the classical integral of the Vening Meinesz [7], or from the spherical harmonic coefficient of the earth gravity field [8]. However, in this work, the components of the deflection of the vertical are determine from the integration of Global Positioning System (GPS) with precise levelling, which is termed the geometric method procedure that was developed by [9]. In our quest to validate the process, a test station (SVG GPS 002) situated with the Rivers State University within the study area was adopted. The justification of the research is to determine the magnitude of the component of the deflection of the vertical within the study area, and to investigate it implication in geodetic measurement. The study is predicated with the following objectives:

1. To determine the geodetic curve distance and azimuth between the stations

2. To determine the components of the deflection of the vertical using the observation equation method of least squares adjustment and associated statistical indicator of the standard deviation.

3. To compute the component of the deflection of the vertical of the study area using geopotential models of the earth gravity field (EGM, 2008, 1996 and 1984) and compare with the geometrically obtained deflection of the vertical.

4. To carry out a two-tailed test of variance for the statistic (chi square) at $95 \%$ confidence interval.

5. To investigate the influence of the deflection of the vertical on geodetic measurement

\section{Study Area}

The study area is situated between Latitude $04^{\circ} 15^{\prime} \mathrm{N}$ to $04^{\circ} 25^{\prime} \mathrm{N}$ of the equator and Longitude $05^{\circ} 20^{\prime} \mathrm{E}$ and $07^{\circ} 15^{\prime} \mathrm{E}$ from Greenwich meridian The study area covers about eight local government area of Rivers State, which is known as the Greater Port Harcourt City Development Authority (GPHC), South-South of Nigeria as shown in Figure 1. It covers an area approximate area of 10,900 Kilometer Squares (734 miles Square).Greater Port Harcourt which comparises eight (Port Harcourt, Oyigbo, Okrika, Ogu-Bolo, ObioAkpor, Ikwerre, Etche, and Eleme) local government out of the twenty three (23) local government in Rivers State. However, the test station (SVG GPS 002) on which the component of the deflection of the vertical will be determined is within the Faculty of Environmental Science, of the Rivers State University Main Campus. 


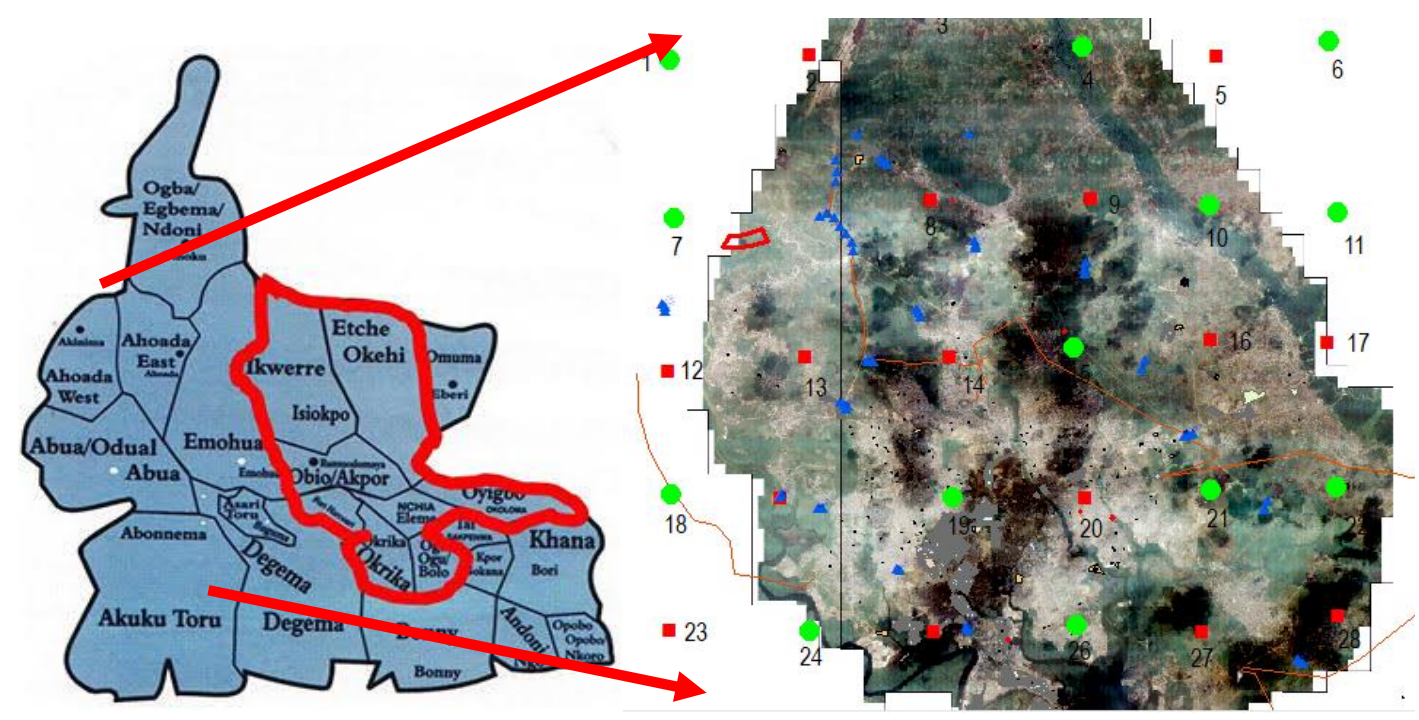

Figure 1. A Schematic Map Showing the Study Area.

\section{Material and Methods}

The data used for this research was obtained from Greater Port Harcourt City Authority. This data was determined using satellite method (using differential GPS positioning techniques and conventional survey methods (precise levelling) during the Mapping of Part of Greater Port Harcourt City by the State Government in 2009 [10] as shown in Table 1 . The following materials were used in this study, MATLAB $4^{\text {th }}$ Level Programming Language, Micro-Soft Excel 2013, GeoidEval Software and Australian Geosciences Software for the solution of the Direct and Inverse Problem of Geometric Geodesy (available online at http: www.geodesyapp.ga.gov.au/Vincenty-inverse).

Table 1. Showing a Sample of the Data (Source: Greater Port Harcourt Development Authority, 2009)

\begin{tabular}{|c|c|c|c|c|c|c|}
\hline STN & $\begin{array}{c}\text { LAT. } \\
(\mathrm{dec} . \mathrm{deg})\end{array}$ & $\begin{array}{c}\text { LONG. } \\
(\mathrm{dec} . \mathrm{deg})\end{array}$ & EASTINGS & NORTHINGS & $\begin{array}{c}\text { M.S.L. } \\
\text { HEIGHT(m) }\end{array}$ & $\begin{array}{c}\text { ELLIP. } \\
\text { HEIGHT(m) }\end{array}$ \\
\hline GPS001 & 5.0384 & 7.0027 & 278562.455 & 557256.887 & 29.513 & 47.654 \\
\hline GPS 02 & 4.98834 & 7.00544 & 278846.155 & 551710.235 & 24.294 & 42.542 \\
\hline GPS 03 & 4.97225 & 6.95118 & 272821.85 & 549949.018 & 20.63 & 38.771 \\
\hline GPS 04 & 4.98817 & 6.95968 & 273770.193 & 551706.979 & 23.096 & 41.357 \\
\hline GPS 05 & 4.97687 & 6.95053 & 272751.332 & 550460.253 & 21.289 & 39.485 \\
\hline GPS 06 & 4.96842 & 6.95077 & 272775.056 & 549525.528 & 20.218 & 38.351 \\
\hline GPS 07 & 4.95495 & 6.94708 & 272361.105 & 548036.898 & 16.476 & 34.627 \\
\hline GPS 08 & 4.95378 & 6.94428 & 272050.092 & 547908.448 & 18.648 & 36.819 \\
\hline GPS 09 & 4.97802 & 6.96892 & 274791.688 & 550581.147 & 20.165 & 38.155 \\
\hline GPS 10 & 4.97662 & 6.97037 & 274952.056 & 550425.802 & 21.445 & 39.661 \\
\hline GPS 11 & 4.97517 & 6.97196 & 275127.938 & 550264.88 & 22.342 & 40.589 \\
\hline GPS 12 & 4.95314 & 6.95045 & 272734.325 & 547834.434 & 17.181 & 35.359 \\
\hline GPS 13 & 4.94971 & 6.95284 & 272998.286 & 547455.335 & 16.58 & 34.766 \\
\hline GPS 14 & 4.94659 & 6.95511 & 273249.041 & 547109.461 & 16.568 & 34.756 \\
\hline GPS 15 & 4.94301 & 6.95738 & 273499.642 & 546712.71 & 16.592 & 34.790 \\
\hline
\end{tabular}




\subsection{Theoretical Framework}

\section{- Geometric Methods}

The combination of space positioning techniques such as the Global Positioning System (GPS) and precise levelling in the determination of the deflection of the vertical using relevant mathematical models is called the geometric method. The geodetic latitude, longitude and height (ellipsoidal height) can be obtained from GPS Observation and the orthometric heights from precise levelling. These quantities are used to determine the component of the deflection of the vertical [9]. The mathematical models that relate these quantities to the component of the deflection of the vertical are discussed.

\section{- Calculation of Deflection of the Vertical Components using the Geometric Method}

The diagram as shown in Figure 2 schematically expressed the relationship between the geoid undulation $(\mathrm{N})$, and the deflection of the vertical $(\varepsilon)$. It demonstrates the deviation between the direction of the vertical and the normal to the ellipsoid.

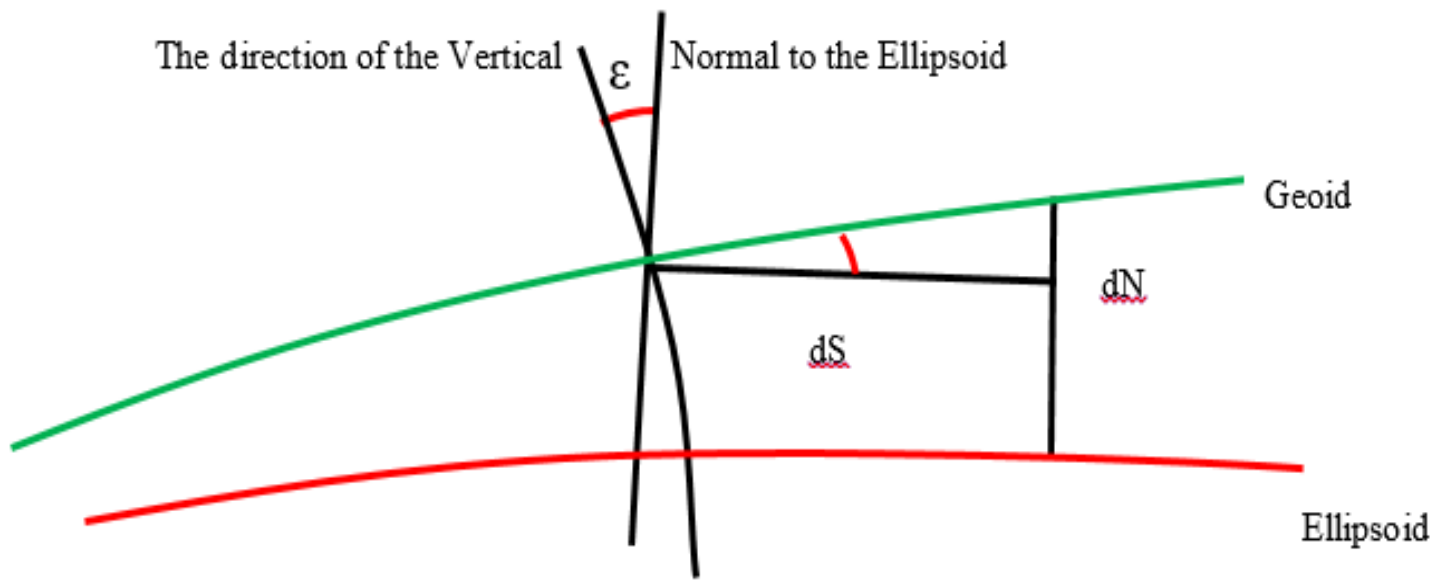

Figure 2. Showing the Relationship between Geoidal undulation and the Deflection of the Vertical (Source; [7]).

The differential relationship between the geoid height and the deflection of the vertical is defined through the following formulae as given by [7][3][4].

$$
\begin{aligned}
& d N=-\varepsilon \cdot d s \\
& \varepsilon=-\frac{d N}{d S}
\end{aligned}
$$

Deflection of the vertical of any geodetic azimuth $(\alpha)$ direction can be calculated as follows, using the north-south and east-west component as given by [3] and shown in equation 3:

$$
\varepsilon=\xi \cdot \cos \alpha+\eta \cdot \sin \alpha
$$

Substituting equation 3 into equation 2;

$$
-\frac{d N}{d S}=\xi \cdot \cos \alpha+\eta \cdot \sin \alpha
$$


When the differential element in the equation 4 are replaced by the difference values obtained in geodetic measurement, the resultant expression will be as in equation 5 :

$$
-\frac{\Delta N}{\Delta S} \approx \xi \cdot \cos \alpha+\eta \cdot \sin \alpha
$$

On the surface of the earth, for any point $A$ and point $B$ close to each other, geoid heights are defined in terms of ellipsoidal height $(\mathrm{h})$ and orthometric heights $(\mathrm{H})$, using the following formulae:

$$
N_{A}=h_{A}-H_{A}
$$

And,

$$
N_{B}=h_{B}-H_{B}
$$

Subtraction of equation 7 from equation 6 gives the geoid height difference $\left(\Delta N_{A B}\right)$ between point $\mathrm{A}$ and point $\mathrm{B}$, as shown in equation 8:

$$
\Delta N_{A B}=N_{A}-N_{B}=\Delta h_{A B}-\Delta H_{A B}
$$

Substituting equation 8 into equation 5 , gives equation 9 as:

$$
-\frac{\Delta h_{A B}-\Delta H_{A B}}{\Delta S} \approx \xi \cdot \cos \alpha+\eta \cdot \sin \alpha
$$

Where $\Delta H$, is the difference in height between point $\mathrm{A}$ and Point $\mathrm{B}$, obtain from orthometric levelling, $\Delta h$ is the difference in ellipsoidal height between point $\mathrm{A}$ and point B, obtained from GPS observations. The two variables $(\xi$ and $\eta$ ) are the component of the deflection of the vertical and $\boldsymbol{\alpha}$ is the geodetic azimuth between point $\mathrm{A}$ and point $B$. In the geometric method, the component of the deflection of the vertical of a station cannot be determined directly. In other to determine the component of the deflection of the vertical for a test station, there is a need to establish stations around the test station called the axillary stations. The test station is the station which the vertical deflection is to be determined. These axillary stations are established at large distance away from the test station [11].

Substituting equation 3 into equation 9, gives equation 10 as:

$$
-\frac{\Delta h_{A B}-\Delta H_{A B}}{\Delta S}=\varepsilon
$$

In the determination of the error propagation in the deflection of the vertical using the geometric techniques, we are assuming the ellipsoidal height and the orthometric height are not correlated, then the covariance matrix can be determined as shown in equation 11 [11]. 


$$
\varepsilon=\frac{\left(\sigma^{2} \Delta h_{A B}+\sigma^{2} \Delta H_{A B}\right)}{\Delta S^{2}}+\frac{\left(\Delta h_{A B}+\Delta H_{A B}\right)}{\Delta S^{2}} \sigma^{2} \Delta S
$$

The second terms tend to zero as the distance of separation increases, hence ignoring the second-degree terms; equation 12 becomes:

$$
\varepsilon=\frac{\left(\sigma^{2} \Delta h_{A B}+\sigma^{2} \Delta H_{A B}\right)}{\Delta S^{2}}
$$

From equation 12, it is clearly seen that the error in determining the deflection of the vertical using the geometric techniques is linearly proportional to the errors of the GPS and precise levelling measurements.

\section{- The Method of Least Squares}

The method of least squares is both an adjustment technique and a statistical tool use in the determination of the most probable value of a given physical quantities by minimizing the sum of the squares of the weighted residual [12]. The observation equation approach was used for the determination of the components of the deflection of the vertical. Observation equation shows the functional relationship between the observed parameter and the adjusted parameters [13].

The functional model (observation equation) between the observe parameter ( $\Delta H, \Delta h, \Delta S$ and $\alpha$ ) and the unknown parameter ( $\eta$ and $\xi$ ) was developed as shown in the models below:

$$
\begin{aligned}
& \xi \cos \alpha_{T A 1}+\eta \sin \alpha_{T A 1}=\frac{\Delta h_{T A 1}-\Delta H_{T A 1}}{\Delta S_{T A 1}} \\
& \xi \cos \alpha_{T A 2}+\eta \sin \alpha_{T A 2}=\frac{\Delta h_{T A 2}-\Delta H_{T A 2}}{\Delta S_{T A 2}} \\
& \xi \cos \alpha_{T A 3}+\eta \sin \alpha_{T A 3}=\frac{\Delta h_{T A 3}-\Delta H_{T A 3}}{\Delta S_{T A 3}} \\
& \xi \cos \alpha_{T A 21}+\eta \sin \alpha_{T A 21}=\frac{\Delta h_{T A 21}-\Delta H_{T A 21}}{\Delta S_{T A 21}}
\end{aligned}
$$

Where, $\xi$ is the component of the deflection of the vertical in the north-south direction, $\eta$, is the component of the deflection of the vertical in east -west direction, $\alpha$ is the geodetic azimuth, the subscript $\mathrm{T}$ represent the test station while A1 represent the first auxiliary stations. $\Delta H, \Delta h, \Delta S$ Represent the difference in orthometric height, the difference in ellipsoidal height and geodetic distance respectively.

According to [12-17], the following mathematical models as given in equations (1722) holds true for a linear case of the observation equation model of least squares adjustment: 


$$
\begin{aligned}
& \hat{x}=\left(A^{T} P A\right)^{-1} A^{T} P L^{b} \\
& V=A \hat{x}+L^{b} \\
& \sigma_{0}^{2}=\left(\frac{\mathrm{V}^{\mathrm{T}} \mathrm{PV}}{\mathrm{n}-\mathrm{m}}\right) \\
& \sum \widehat{\mathrm{X}}=\sigma^{\circ}\left(\mathrm{A}^{\mathrm{T}} \mathrm{PA}\right)^{-1} \\
& L^{a}=L^{b}+V \\
& \sum L^{a}=A \sum \hat{x} A^{T}
\end{aligned}
$$

Equation (19) gives the unit weight variance and tells us about the fitness of the adjustment model to the observation [13]. It is called the a-posterior variance, Equation (20) is the variance-covariance matrix, it is fundamentally important because, the diagonal element yield the variance of the adjusted parameter, from which we can determine the standard deviation as a measure of the precision of the observation. From equation (21) the adjusted observation can be determined and equation (22) is the covariance matrix of the adjusted observation. Where, $\hat{x}$ is a vector of adjusted (Unknown) parameters, $L^{b}$ is a vector of original observations, and $\mathrm{A}$ is the design matrix, $\mathrm{v}$ is the vector of residual, $\mathrm{P}$ is the weight matrix, $\mathrm{n}$ is the number of observations, $\mathrm{m}$ is the number of unknown parameter $(n-m)$ is actually the degree of freedom or redundancy.

\section{Results and Discussion on Findings}

For this study, [18] iterative algorithm based on the online software developed by the Australia Geoscience (2003) was used to compute for the geodetic distance and azimuth between the twenty-one (21) baselines, while the difference in both ellipsoidal height and orthometric, this was done using Micro Soft excel 2013. The result is as shown in Table 2. This satisfies objective one of this study.

\subsection{Comparison of the GPS/Levelling Computed Vertical Deviation with deviation of the Vertical Obtained from Global Geopotential Models}

The observed geodetic latitude and longitude of the stations were used to compute the EGM2008, EGM96 and EGM84 geoid heights of the stations. The EGM2008, EGM96 and EGM84 geoid heights were calculated using GeoidEval Software and UNAVCO geoid calculator. GeoidEval Version 1.51 computes the heights of the geoid above the WGS84 ellipsoid using in a grid of values of the earth gravity model [19].

The geoidal undulation obtained from the three Geopotential models was used for the computation of the deflection of the vertical according to equation (4) using the method of least squares by the method of observation equation. The result is as shown in Table 3 and in Figure 3. This satisfies objective three (3) of this study. 
Table 2. Showing the Computed Geodetic Distance and Azimuth

\begin{tabular}{|c|c|c|c|c|c|}
\hline Station From & $\begin{array}{c}\text { Latitude (Decimal } \\
\text { of Degrees) }\end{array}$ & $\begin{array}{c}\text { Longitude (Deci- } \\
\text { mal of Degrees) }\end{array}$ & $\begin{array}{c}\text { Geodetic Dis- } \\
\text { tance (meters) }\end{array}$ & $\begin{array}{c}\text { Forward Azimuth } \\
\text { (Decimal of Degrees) }\end{array}$ & $\begin{array}{c}\text { Station To } \\
\text { SVG }\end{array}$ \\
\hline SVG GPS002 & 4.80014 & 6.98001 & & & GPS002 \\
\hline SVG GPS002 & 5.03848 & 7.00273 & 26476 & 5.46058 & GPS001 \\
\hline SVG GPS002 & 4.98834 & 7.00544 & 21001.4 & 7.71737 & GPS002 \\
\hline SVG GPS002 & 4.97225 & 6.95118 & 19298.7 & 350.463 & GPS003 \\
\hline SVG GPS002 & 4.98817 & 6.95968 & 20914.3 & 353.811 & GPS004 \\
\hline SVG GPS002 & 4.95378 & 6.94428 & 17445.5 & 346.871 & GPS008 \\
\hline SVG GPS002 & 4.97517 & 6.97196 & 19375.4 & 357.359 & GPS011 \\
\hline SVG GPS002 & 4.95313 & 6.95045 & 17232.3 & 349.033 & GPS012 \\
\hline SVG GPS002 & 4.94971 & 6.95284 & 16811.7 & 349.674 & GPS013 \\
\hline SVG GPS002 & 4.89316 & 6.96472 & 10424.8 & 350.637 & GPS017 \\
\hline SVG GPS002 & 4.87564 & 6.95483 & 8803.36 & 341.503 & GPS021 \\
\hline SVG GPS002 & 4.8766 & 6.95283 & 8976.16 & 340.375 & GPS023 \\
\hline SVG GPS002 & 4.83244 & 6.94489 & 5285.08 & 312.513 & GPS025 \\
\hline SVG GPS002 & 4.83648 & 6.92827 & 7006.18 & 304.998 & GPS027 \\
\hline SVG GPS002 & 4.94228 & 7.00802 & 16021.8 & 11.1801 & GPS031 \\
\hline SVG GPS002 & 4.9351 & 7.05356 & 17008.1 & 28.6606 & GPS035 \\
\hline SVG GPS002 & 4.89461 & 7.07747 & 15033.1 & 45.978 & GPS037 \\
\hline
\end{tabular}

Table 3. Showing the difference between the geometric geoid undulation and the gravimetric Geoid undulation computed from the Various Geopotential Models (EGM Models)

\begin{tabular}{|c|c|c|c|c|c|c|c|c|c|}
\hline STN ID & LAT. & LONG. & Geom. (N) & EGM2008 & Diff. & EGM96 & Diff. & EGM84 & Diff. \\
\hline GPS001 & 4.80014 & 6.98001 & 18.420 & 18.9838 & -0.564 & 18.8574 & -0.437 & 21.2569 & -2.837 \\
\hline GPS002 & 5.03848 & 7.00273 & 18.140 & 18.8683 & -0.728 & 18.7851 & -0.645 & 21.7041 & -3.564 \\
\hline GPS003 & 4.98834 & 7.00544 & 18.250 & 18.9030 & -0.653 & 18.7985 & -0.549 & 21.6047 & -3.355 \\
\hline GPS004 & 4.97225 & 6.95118 & 18.140 & 18.8317 & -0.692 & 18.741 & -0.601 & 21.5229 & -3.383 \\
\hline GPS008 & 4.98817 & 6.95968 & 18.260 & 18.8328 & -0.573 & 18.7434 & -0.483 & 21.5595 & -3.300 \\
\hline GPS011 & 4.95378 & 6.94428 & 18.170 & 18.8358 & -0.666 & 18.7432 & -0.573 & 21.4845 & -3.315 \\
\hline GPS012 & 4.97517 & 6.97196 & 18.250 & 18.8598 & -0.610 & 18.763 & -0.513 & 21.5454 & -3.295 \\
\hline GPS013 & 4.95313 & 6.95045 & 18.180 & 18.8445 & -0.664 & 18.7499 & -0.570 & 21.4879 & -3.308 \\
\hline GPS017 & 4.94971 & 6.95284 & 18.190 & 18.8505 & -0.661 & 18.7541 & -0.564 & 21.4836 & -3.294 \\
\hline GPS021 & 4.89316 & 6.96472 & 18.280 & 18.9026 & -0.623 & 18.7951 & -0.515 & 21.3944 & -3.114 \\
\hline GPS023 & 4.87564 & 6.95483 & 18.300 & 18.9045 & -0.604 & 18.7971 & -0.497 & 21.3599 & -3.060 \\
\hline GPS025 & 4.8766 & 6.95283 & 18.390 & 18.9017 & -0.512 & 18.795 & -0.405 & 21.3603 & -2.970 \\
\hline GPS027 & 4.83244 & 6.94489 & 18.280 & 18.9292 & -0.649 & 18.8174 & -0.537 & 21.2889 & -3.009 \\
\hline GPS031 & 4.83648 & 6.92827 & 18.270 & 18.9112 & -0.641 & 18.8052 & -0.535 & 21.2876 & -3.018 \\
\hline GPS035 & 4.94228 & 7.00802 & 18.280 & 18.9336 & -0.654 & 18.8152 & -0.535 & 21.516 & -3.236 \\
\hline GPS037 & 4.9351 & 7.05356 & 18.360 & 19.0033 & -0.643 & 18.8671 & -0.507 & 21.5426 & -3.183 \\
\hline GPS039 & 4.89461 & 7.07747 & 18.390 & 19.0471 & -0.657 & 18.8995 & -0.509 & 21.4832 & -3.093 \\
\hline GPS041 & 4.86345 & 7.09513 & 18.420 & 19.0774 & -0.657 & 18.9209 & -0.501 & 21.4374 & -3.017 \\
\hline GPS044 & 4.83205 & 7.12673 & 18.500 & 19.1212 & -0.621 & 18.9526 & -0.453 & 21.4032 & -2.903 \\
\hline GPS052 & 4.76941 & 7.14117 & 18.500 & 19.1393 & -0.639 & 18.9691 & -0.469 & 21.2987 & -2.799 \\
\hline GPS054 & 4.78232 & 7.00546 & 18.470 & 19.0168 & -0.547 & 18.8802 & -0.410 & 21.239 & -2.769 \\
\hline & & & & RMS & 0.663 & & 0.5405 & & 3.291 \\
\hline
\end{tabular}


The design matrix (A) and the matrix of observation $\left(L^{b}\right)$ which was developed using the functional models as given in equation 13 to equation 16 is given as:

$A=\left[\begin{array}{ll}0.99546 & 0.09516 \\ 0.99094 & 0.13429 \\ 0.98618 & -0.16677 \\ 0.99417 & -0.10780 \\ 0.97386 & -0.22715 \\ 0.99894 & -0.04608 \\ 0.98174 & -0.19025 \\ 0.98381 & -0.17924 \\ 0.9867 & -0.1627 \\ 0.9419 & -0.3173 \\ 0.67576 & -0.3559 \\ 0.57354 & 0.73712 \\ 0.98102 & -0.81918 \\ 0.87748 & 0.19389 \\ 0.69493 & 0.47862 \\ 0.48078 & 0.71907 \\ 0.48078 & 0.87684 \\ 0.21197 & 0.97728 \\ -0.18664 & 0.98243 \\ -0.57242 & 0.81996 \\ 0.75885 & -0.65126\end{array}\right] \quad \mathrm{L}^{\mathrm{b}}=\left[\begin{array}{l}-0.00082 \\ -0.00078 \\ -0.00066 \\ -0.00073 \\ -0.00062 \\ -0.00062 \\ -0.00075 \\ -0.00054 \\ -0.000297 \\ -0.000803 \\ -0.000842 \\ 0.001251 \\ 0.000845 \\ 0.000762 \\ -0.00736 \\ -0.000722 \\ -0.000815 \\ -0.000482 \\ -0.000364 \\ -0.000343 \\ -0.000326\end{array}\right]$

The computation of the component of the deflection of the vertical using the method of Least Squares by the observation equation; MATLAB program was used to facilitate the computational process; the results are given:

The Normal equation matrix is given as:

$$
A^{T} P A=\left[\begin{array}{cc}
14.7872 & -1.8262 \\
-1.8262 & 6.2128
\end{array}\right]
$$

The adjusted Parameter is computed from equation 17 and is given as:

$$
\hat{X}=\left[\begin{array}{l}
\xi \\
\eta
\end{array}\right]=\left[\begin{array}{c}
000^{0} 00^{\prime} 0.0473^{\prime \prime} \\
-000^{0} 00^{\prime} 0.0393^{\prime \prime}
\end{array}\right]
$$

The a-posterior variance given in equation 19 as:

$$
\sigma_{0}^{2}=\left(\frac{V^{T} P V}{n-m}\right)=6.4770 e-11
$$

The a-posterior standard error $\sigma=\sqrt{\frac{V^{T} P V}{n-m}}=8.0480 e-06$ 
In line with objective two (2) of this work, the variance-covariance matrix of the adjusted parameter is given as in equation 22 as:

$$
\sum_{\hat{X}}=\left[\begin{array}{ll}
0.00000000000455 & 0.00000000000314 \\
0.00000000000314 & 0.00000000001082
\end{array}\right]
$$

and the Standard error which is the square root of the variance (the diagonal element of the variance-covariance matrix) is given as:

$$
\left[\begin{array}{l}
\xi \\
\eta
\end{array}\right]=\left[\begin{array}{c}
0.0473^{\prime \prime} \pm 0.0093^{\prime \prime} \\
-0.0393^{\prime \prime} \pm 0.0060^{\prime \prime}
\end{array}\right]
$$

From the two (2) components of the deflection of the vertical, the total deviation of the vertical is given as:

$$
\varepsilon=\sqrt{\xi^{2}+\eta^{2}}=0.0615^{\prime \prime}
$$

\subsection{Test of Hypothesis}

A test of Hypothesis of the obtained result was done to check if the so obtained result and the procedures used can be relied upon. That is $V^{T} P V$ is statistically tested to see whether it falls within the specified confidence limit or not [12]. This is done by means of a two-tailed test of variance chi square $\chi^{2}$ test. The formation of the hypothesis is as follows:

$$
H_{0}: \sigma=V^{T} P V, H_{1} ; \sigma^{2} \neq V^{T} P V
$$

The zero-hypothesis state that the a-prior variance of the unit weight statistically equals the a-posterior variance of unit weight. If the zero hypothesis is accepted, the statistics are judge to be correct. But if the numerical value is such that:

$$
\chi^{2} \prec \chi_{n-1,1-\frac{a}{2}}^{2}, \chi^{2} \prec \chi_{n-r, \frac{a}{2}}^{2}
$$

the zero hypothesis is rejected. This is a two-tailed test where the alternative hypothesis $\left(H_{1}\right)$ is rejected if the computed statistics are outside the confidence limit. The confidence limit is the upper limit and the lower limit of the statistic table. The result of the hypothesis testing reveals that at 0.05 level of significance $(\alpha)$, with a degree of freedom of 19 . The computed value for the chi square is given as in equation 25 [16]:

$$
\chi^{2}=\frac{V^{T} P V}{\sigma_{0}^{2}}(n-r)=14.2504
$$

The lower limit and the upper limit are obtained from the statistical table is given as 8.907 and 32.851 respectively. This satisfies objective four (4) of this research.

Table 4. Showing the Comparison of the deflection component obtained from GPS/Levelling method \& Earth Gravity Model 


\begin{tabular}{|c|c|c|c|c|}
\hline \multicolumn{5}{|c|}{ Comparison of the deflection of the Vertical } \\
\hline & North-South & East-West Compo- & \multicolumn{2}{|c|}{ Difference } \\
\cline { 3 - 5 } Methods & Component & nent & $\xi\left({ }^{\prime \prime}\right)$ & $\eta\left({ }^{\prime \prime}\right)$ \\
\hline Geometric Method & $0.0473^{\prime \prime}$ & $-0.0393^{\prime \prime}$ & & \\
\hline EGM 08 Model & $0.0204^{\prime \prime}$ & $-0.0345^{\prime \prime}$ & $0.0269^{\prime \prime}$ & $-0.0048^{\prime \prime}$ \\
\hline EGM96 Model & $0.0157^{\prime \prime}$ & $-0.0246^{\prime \prime}$ & $0.0316^{\prime \prime}$ & $-0.0147^{\prime \prime}$ \\
\hline EGM 84 Model & $-0.0546^{\prime \prime}$ & $-0.0208^{\prime \prime}$ & $0.1019^{\prime \prime}$ & $-0.0185^{\prime \prime}$ \\
\hline
\end{tabular}

Table 5. Showing the result of the deflection of the vertical as computed by different researchers at various locations within and outside Nigeria

\begin{tabular}{|c|c|c|c|c|c|}
\hline Researcher & Location & Method & $\begin{array}{l}\text { No. of } \\
\text { Com- }\end{array}$ & \multicolumn{2}{|c|}{$\begin{array}{c}\text { Components of Deflection of the } \\
\text { Vertical }\end{array}$} \\
\hline \multirow{5}{*}{$\begin{array}{l}\text { Basil and Hart, } \\
\text { (2021) }\end{array}$} & \multirow{5}{*}{$\begin{array}{c}\text { Part of Rivers } \\
\text { State }\end{array}$} & & & North/South (६) & East/West (n) \\
\hline & & GPS/Level & & $0.0473 " \pm 0.0093 "$ & - 0.0393" $\pm 0.0060 "$ \\
\hline & & EGM 2008 & 21 & $0.0204^{\prime \prime} \pm 0.0008814^{\prime \prime}$ & $-0.0345^{\prime \prime} \pm 0.0014^{\prime \prime}$ \\
\hline & & EGM 1996 & 21 & $0.0157^{\prime \prime} \pm 0.000755^{\prime \prime}$ & $-0.0246^{\prime \prime} \pm 0.0012^{\prime \prime}$ \\
\hline & & EGM 1984 & 21 & $-0.0546 " \pm 0.0006014$ & $-0.0208^{\prime \prime} \pm 0.0006014^{\prime \prime}$ \\
\hline $\begin{array}{l}\text { Maduafor et al, } \\
\text { (2019). }\end{array}$ & Imo State & $\begin{array}{c}\text { GPS/ } \\
\text { Levelling }\end{array}$ & & $-0.0286 " \pm 5.5911 \mathrm{e}-005$ & $-0.0001^{\prime \prime} \pm 0.0009278^{\prime \prime}$ \\
\hline $\begin{array}{l}\text { Odoyebo et al. } \\
(2016)\end{array}$ & $\begin{array}{l}\text { Ugbowo, Benin } \\
\text { city }\end{array}$ & $\begin{array}{c}\text { GPS/ } \\
\text { Levelling }\end{array}$ & 15 & $-0.550^{\prime \prime} \pm 0.000001^{\prime \prime}$ & $-0.395 " \pm 0.0000006^{\prime \prime}$ \\
\hline Ameh (2013). & Lobi, Makurdi & GPS/ Level & & $-3.18^{\prime \prime} \pm 0.60^{\prime \prime}$ & $-2.25 " \pm 0.43 "$ \\
\hline $\begin{array}{l}\text { Kantomah } \\
(2010)\end{array}$ & ABU Zaria & GPS/Level & & $-0.04462^{\prime \prime}$ & $0.0575856 "$ \\
\hline Tse and Baki & Hong Kong & $\begin{array}{c}\text { GPS/ } \\
\text { Levelling }\end{array}$ & & $-7.3^{\prime \prime} \pm 1.6^{\prime \prime}$ & $5.3^{\prime \prime} \pm 1.3^{\prime \prime}$ \\
\hline Ayhan (2009) & Honya, Turkey & $\begin{array}{c}\text { GPS/ } \\
\text { Levelling }\end{array}$ & 15 & $-4.15^{\prime \prime} \pm 0.61^{\prime \prime}$ & $8.75^{\prime \prime} \pm 0.69^{\prime \prime}$ \\
\hline Tomas (1989) & USA & $\begin{array}{c}\text { GPS/ } \\
\text { Levelling }\end{array}$ & & $5.2^{\prime \prime} \pm 0.10^{\prime \prime}$ & $-2.76 \pm 0.14 "$ \\
\hline Tomas (1989) & USA & $\begin{array}{c}\text { Astrogeo- } \\
\text { detic }\end{array}$ & & $5.19^{\prime \prime} \pm 0.5^{\prime \prime}$ & $-2.58^{\prime \prime} \pm 0.5 "$ \\
\hline
\end{tabular}

Table 6. Showing the effect of the deflection of the vertical on position determination

\begin{tabular}{|c|c|c|c|c|}
\hline Stn & Distance(m) & Diff. in N & Diff. in E & Diff. in U \\
\hline 1 & 1 & -0.000019 & 0.00001338 & -0.0000204 \\
\hline 2 & 100 & -0.001920 & 0.00134 & -0.000205 \\
\hline 3 & 1000 & -0.019200 & 0.0134 & -0.002045 \\
\hline 4 & 10000 & -0.192500 & 0.1338 & -0.02045 \\
\hline 5 & 100000 & -1.924800 & 1.3377 & -0.2045 \\
\hline 6 & 1000000 & -19.248300 & 13.3765 & -2.0446 \\
\hline
\end{tabular}




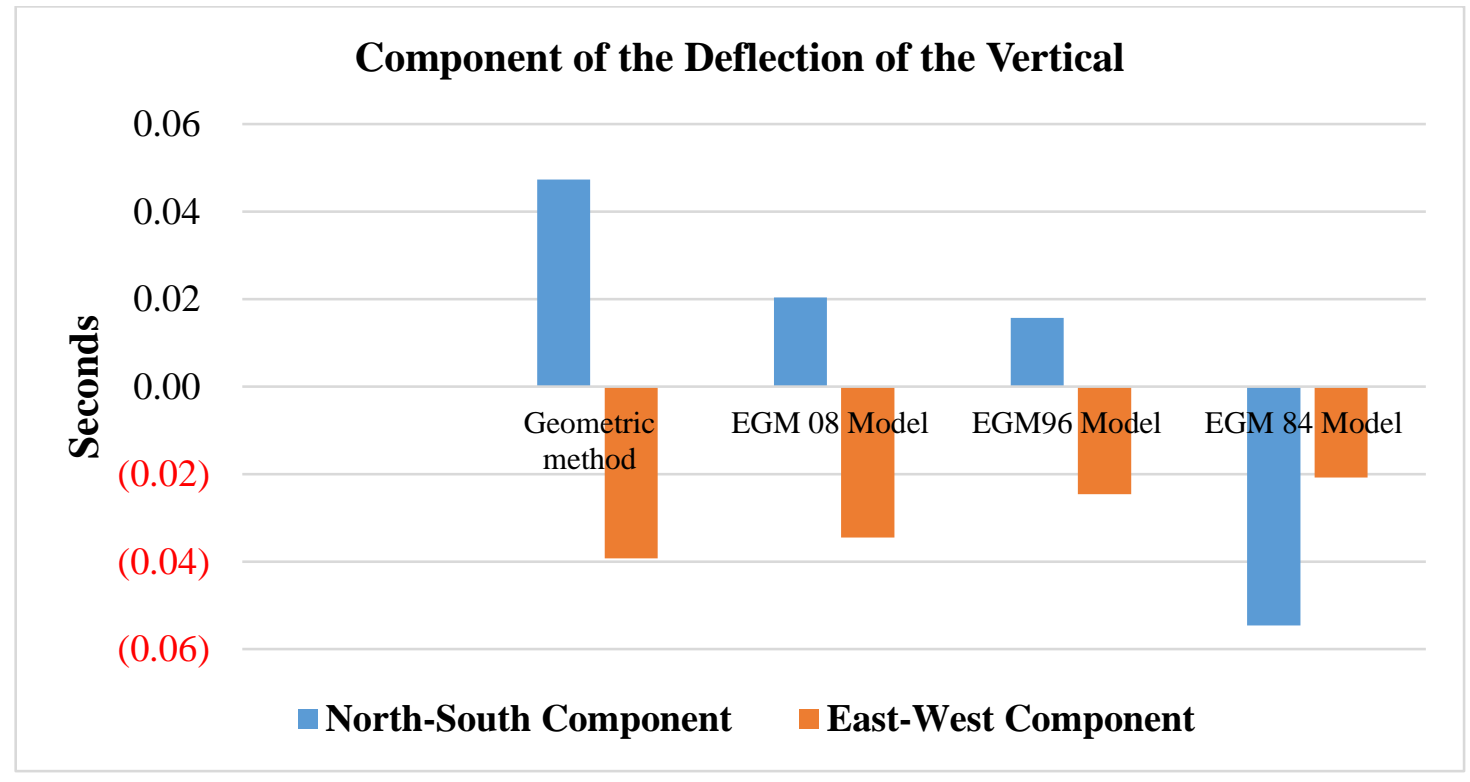

Figure 3. Showing the Comparison between the Geometric Deflection of the Vertical and that obtained from various Geopotential Models.

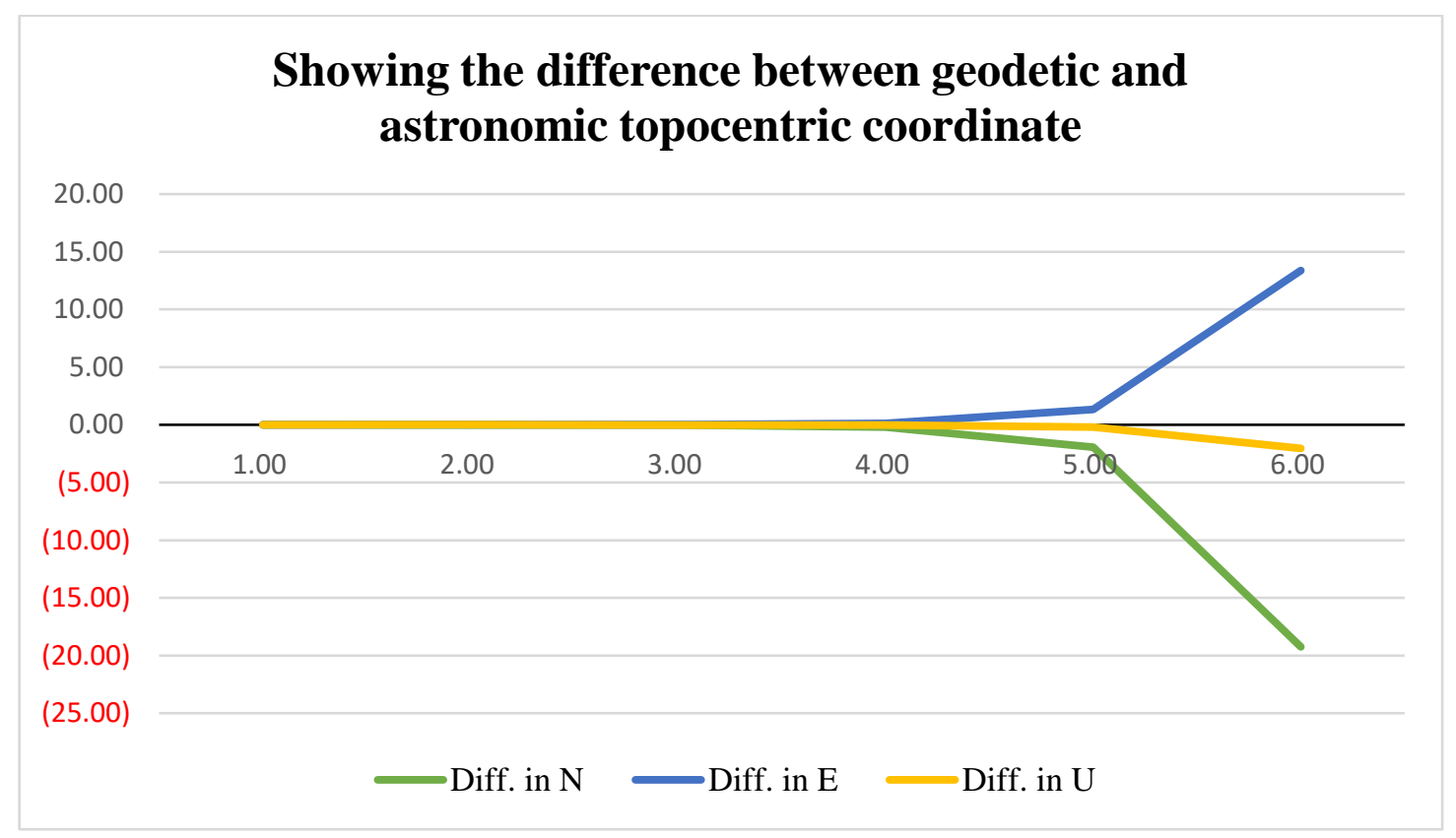

Figure 4. Showing the effect of the deflection of the vertical on position determination.

Using the geometric method as described in this work, the deflection of the vertical of the test station SVG GPS002 located within the Rivers State University Campus is; $0.0473^{\prime \prime}$ and 0.0393 " arc seconds for the north-south and east-west components respectively. The a-posteriori variance and the a-posteriori standard error were also respectively computed to be $0.0000001429^{\prime \prime}$ and $\pm 0.0227^{\prime \prime}$. The standard errors of the determined components of deflection of the vertical are $\pm 0.0093^{\prime \prime}$ and $\pm 0.00060^{\prime \prime}$ for north-south and eastwest directions respectively. The maximum and the minimum residuals were computed to be 0.00002077 and -0.00000482 respectively.

As already established in literatures [20,21], the geometric method gives the most optimal result for the determination of the components of the deflection of the vertical. 
However, as can be seen in Table 4, the components of the deflection of the vertical obtained from EGM 2008 are closest to the geometrically derived deflection of the vertical than EGM 96 and 84. This is because of high truncation error in the spherical harmonic coefficient of EGM 96 and 84. Table 5 gives the value of the deflection of the vertical obtained by various researchers within Nigeria and around the world. It can be seen that the component of the deflection of the vertical is indeed very particularly small in the southern region of Nigeria. However, [22] discovered a significantly high values of the deflection in Makurdi which is in the north-east region of Nigeria. This is probably due to the presence of high mountainous terrain that characterized the northern region of Nigeria. The statistical test of variance by means of the chi-squares test is 14.2504, which was within the confidence interval with lower and upper limits of 8.907 and 32.851 respectively. The result shows that the procedures and the computed statistic can be relied upon within $95 \%$ confidence interval.

\section{Conclusion}

On the investigation of the effect of the deflection of the vertical on position determination, it can be seen from Table 6 that the difference between the astronomic and the geodetic topocentric coordinate increases with distances from the origin as shown in Figure 4 . This underscores the need to apply the components of the deflection of the vertical in geodetic network origin as this will impact on high precision geodetic mapping applications such as an underground engineering surveying, hydro electrical construction monitoring, international and intercontinental boundary delineation, etc. This is more critical when GNSS derived coordinates obtained directly will be required to be integrated into traditional three-dimensional terrestrial geodetic measurements for position determination.

\section{Reference}

[1] Fajemirokun F.A. (1981): “On the Problems of Local Origins in Nigeria” The Map Maker, Journal of the Nigerian Institution of Surveyors, Vol. 7, No1, July. Proceedings of the XVITH Annual General Meeting of the Nigerian Institution of Surveyors in Lagos, Lagos State, 21st - 24th April.

[2] Hart, L (2015). Development of Datum Transformation Procedure for Nigeria Based on National Transformation Version 2 (NTv2) Model. An Unpublished Ph.D Thesis, submitted to the Department of Geoinformatics and Surveying, University of Nigeria, Enugu Campus, Nigeria.

[3] Fubara M. J., Fajimirokun F. A., Ezeigbo, (2014). Fundamental of Geodesy. Concept Publication Limited. 77, Shipeolu Street, Palmgrove, Lagos, Nigeria. ISBN: 978-987-525562-1-5.

[4] Agajelu S.I. (2018). Geodesy the Basic Theories-Classical and Contemporary, EL'DEMAK Publishing, 76 Robinson Street, Uwani, Enugu, ISBN.978-978-8436-99-0.

[5] Featherstone E. W. (1999). The Use and Abuse of the Vertical Deflections. A Conference Paper Presented at the Sixth South East Asian Surveyor's Congress, Fremantle, Western Austral.

[6] Thomson Donald B. (1978). Introduction to Geodetic Astronomy. Lecture note 49, Department of Geodesy and Geomatics Engineering, University of New Brunswick P.O. Box 4400 Federation, N.B., Canada

[7] Bernhard Hofmann-Wellenhof and Helmut Moritz (2006). Physical Geodesy.2nd Edition. Springer-Verlag Wien, New York. ISBN: 13 978-3-211-33544-4.

[8] Jekeli C. (1999). An Analysis of Vertical Deflections Derived from High Degree Spherical Harmonic Model. Journal of Geodesy, Springer-Verlag.

[9] Soler T, Carslon A. E \& Evans A. G., (1989). Determination of Vertical Deflections Using the Global Positioning System and Geodetic Leveling, Geophysical. Res. Latter. 16(7): ISSN: 695698.

[10] Oba T. (2015). Developing a Local Geoid Model for Part of Rivers State. A MSc. Dissertation submitted to the Post Graduate School, University of Nigeria, Nsukka, Enugu Campus. In partial fulfillment of the requirement for the award of MSc. In Geodesy and Geodynamics.

[11] Ayhan, C. (2009): Determination of the Deflection of Vertical Components via GPS and Levelling Measurement: A Case Study of a GPS Test Network in Konya, Turkey. Scientific Research and Essay Vol.4 (12), pp. 1438-1444, December, 2009 Available online at http://www.academicjournals.org/SRE.

[12] Ghilani C. D. \& Wolf P. R. (2006). Adjustment Computations; Spatial Data Analysis. Published by John Wiley \& Sons, Inc, Hoboken, New Jersay, 4th ed. ISBN-13-978-0-471-69728-2. 
[13] Ayeni, O. O. (1981). Statistical Adjustment and Analysis of Data: (with applications in geodetic surveying and photogrammetry, A Manual, in the Department of Surveying \& Geoinformatics, Faculty of Engineering, University of Lagos, Nigeria.

[14] Uotila U. A., (1967). Introduction to Adjustment Computations with Matrices; Lecture notes (unpublished), Geodetic Science Department, the Ohio State University.

[15] Vanicek, (1980). Introduction to Adjustment Calculus. Unpublished Lecture Note 35, Department of Geodesy and Geomatics Engineering, University of New Brunswick, P.O Box 444 Frederiction, N.B. Canada

[16] Leick, Alfred Lev Rapoport, Dmitry TaTarniko (2015). GPS Satellite Surveying. Fourth Edition. Published by John Wiley \& Sons, Inc., Hoboken, New Jersey. ISBN: 978-1-118-67557-1.

[17] Ogundere J. O. (2019). Understand Least Squares Estimation and Geomatics Data Analysis. John Wiley \& Sons, Inc., 111 Rivers Street, Hoboken, NJ 07030, USA. ISBN: 9781119501442.

[18] Vincenty T., (1975). Direct and Inverse Solutions of Geodesics on the Ellipsoid with application of nested equations" (http://www.ngs.noaa.gov/PUBS_LIB/inverse.pdf)

[19] Uzodinma, V.N., Oguntuase J. O., Onah E.,Chike C., \& Ehigiator R.,(2014). FIG Congress: Engaging the Challenges -Enhancing the Relevance. Kuala Lumpur Malaysia.

[20] VandanBerg D. J., (1999). Combining GPS and Terrestrial Observations to Determine Deflection of the Vertical. A Thesis Submitted to the Faculty of Purdue University.

[21] Chiriac V., (2017). Study of Deflection of the Vertical Determination Methods and the Influence on the Traditional Terrestrial Three-Dimensional Geodetic Measurements.

[22] Ameh B. M. (2013): Determination of Components of Deflection of the Vertical of Lobi Area of Makurdi, Benue State, Using GPS (GNSS) and Precise Levelling Observations. Unpublished MSc. Thesis of the Department of Surveying and Geo- informatics, Nnamdi Azikiwe University Awka. 